\title{
The Pandemic Coping Scale - Factorial Validity and Reliability of a Brief Measure of Coping During a Pandemic
}

\author{
Annett Lotzin ( $\sim$ A.Lotzin@uke.de) \\ University Medical Center Hamburg-Eppendorf \\ Ronja Ketelsen \\ University Medical Center Hamburg-Eppendorf \\ Sven Buth \\ University Medical Center Hamburg-Eppendorf \\ Linda Krause \\ University Medical Center Hamburg-Eppendorf \\ Ann-Kathrin Ozga \\ University Medical Center Hamburg-Eppendorf \\ Maria Böttche \\ Freie Universität Berlin \\ Ingo Schäfer \\ University Medical Center Hamburg-Eppendorf
}

\section{Research Article}

Keywords: COVID-19, pandemic, coping, psychometrics

Posted Date: April 19th, 2021

DOI: https://doi.org/10.21203/rs.3.rs-400361/v1

License: (c) (i) This work is licensed under a Creative Commons Attribution 4.0 International License. Read Full License 


\section{Abstract}

Background: This study aimed to assess the factorial validity and reliability of the Pandemic Coping Scale, a new brief measure of coping behavior in response to the stressors of a pandemic.

Methods: The scale was administered to $\mathrm{N}=2,316$ German participants during the COVID-19 pandemic. An exploratory and a confirmatory factor analysis were applied among two random splits of the sample. The global goodness of fit ( $\chi^{2}$, RMSEA, SRMR, CFI, TLI), the local goodness of fit (factor loadings, communalities, factor reliability, discriminant validity), and test quality criteria (internal consistency, item discrimination, and difficulty) were evaluated for two models (Model 1: four-factor model; Model 2: four-factor model combined with a second-order general factor).

Results: The exploratory factor analysis suggested a four-factor solution with factor loadings accounting for $44.6 \%$ of the total variance (Factor 1 'Healthy Lifestyle', Factor 2 'Joyful Activities', Factor 3 'Daily Structure', Factor 4 'Prevention Adherence'). The confirmatory factor analysis showed a sufficient global fit for both specified models (Model $1: \chi^{2}(59, N=1172)=366.97, p<.001, \mathrm{RMSEA}=.067, \mathrm{SRMR}=.043, \mathrm{CFI}=.926, \mathrm{TLI}=.902 ; \mathrm{Model} 2: \chi^{2}(61, N=1172)=$ $373.33, p<.001, \mathrm{RMSEA}=.066, \mathrm{SRMR}=.043, \mathrm{CFI}=.925, \mathrm{TLI}=.904)$. Model 1 and Model 2 did not significantly differ in their fit to the data $\left(\Delta \chi^{2}(2, N=1172)\right.$ $=6.36, p=.042$ ). Local goodness of fit indices were similar for both models and mostly showed moderate to large factor loadings, and good factor reliabilities except for 'Prevention Adherence'.

Conclusion: The Pandemic Coping Scale showed sufficient factorial validity for the four measured dimensions of coping and reliability for the scales except for 'Prevention Adherence' to assess coping during the current COVID-19 pandemic. The 'Prevention Adherence' subscale might be improved by adding items with higher item difficulties.

\section{Background}

The coronavirus disease 2019 (COVID-19) pandemic is related to multiple stressors that impact the wellbeing of whole populations (Serafini et al., 2020; Usher et al., 2020). In addition to the burden of a COVID-19 infection, the national lockdowns have a drastic impact on everyday life. Social physical contacts are rare, including friends and family gatherings. Structuring the work and daily activities when working from home can be also challenging (Palumbo, 2020; Rubin et al., 2020). Physical activities like cycling to work have been restricted, leisure opportunities such as going to the sports club were often impossible. At the same time, activities like watching television and sitting in front of the computer have increased (Meyer et al., 2020; Ong et al., 2020). Being at home most of the time may promote unhealthy eating habits (Mattioli et al., 2020) and alcohol use (Koopmann et al., 2020; Ramalho, 2020). Being at home for weeks or even months with reduced social contact has increased distress, loneliness, and anxiety (Bäuerle et al., 2020). To reduce the psychological burden of a pandemic, it is important to understand how people cope with these pandemic-specific stressors, and which coping behavior promotes wellbeing.

Coping is defined as a cognitive or behavioral approach to control a situational demand that is stressful (Skinner \& Zimmer-Gembeck, 2016). The term coping is often referred to adaptive coping strategies, i.e., strategies that reduce distress and promote wellbeing and health (Taylor \& Stanton, 2007). For example, engaging in exercising in response to a stressful situation might be seen as adaptive coping, as it may reduce distress and may increase wellbeing. However, some coping strategies may increase distress, and in turn, may be considered maladaptive. For example, smoking in response to a stressful situation could be seen as maladaptive, as it may increase distress and can harm health.

Coping with the multiple stressors in the context of a pandemic or epidemic requires specific coping skills, such as following physical distancing measures, establishing healthy lifestyle behaviors and a daily structure, or seeking social support. Research conducted during the early phase of the COVID-19 pandemic found associations between adaptive coping and reduced symptoms of anxiety and depression (Fullana et al., 2020). Establishing a daily routine, following a healthy diet, and taking the opportunity to pursue hobbies were most strongly related to lower symptoms of depression (Fullana et al., 2020).

To assess coping with the specific stressors during a pandemic or epidemic, a valid and reliable measure is needed. A meta-analysis of coping questionnaires (Kato, 2015) found that the most commonly used measures outside of a pan- or epidemic context were the Coping Orientation to Problems Experienced (COPE; Carver et; al., 1989), the Brief-COPE (Carver, 1997), and the Ways of Coping Questionnaire (WCQ; Folkman \& Lazarus, 1988). During the current COVID19 pandemic, the 60-item COPE (Carver et al., 1989) has rarely been used. Questionnaires with a high number of items might be difficult to be used during a pandemic, as an online-based assessment is required. The shorter Brief-COPE was applied in the general population (Fiorillo et al., 2020; Kalaitzaki, 2020; Zacher \& Rudolph, 2021) and in nursing students (Sheroun et al., 2020) during the current pandemic. For example, Zacher \& Rudolph (2021) found that active coping, positive reframing, seeking emotional support, and religion were related to wellbeing during the early phase of the pandemic. Unexpectedly, the coping behaviors 'planning' and 'humor' were associated with reduced wellbeing, indicating that these coping strategies might be less adaptive during a pandemic compared to non-pandemic situations.

The 66-item Ways of Coping Questionnaire (WCQ; Folkman \& Lazarus, 1988) measures problem-focused and emotion-focused strategies. Studies investigating the psychometric properties of the WCQ revealed heterogenous internal consistencies (Lundqvist \& Ahlström, 2006; Rexrode et al., 2008). Although the WCQ has been widely used in other contexts (Kato, 2015), the WCQ has been rarely applied during the current pandemic. Salopek-Žiha et al. (2020) found that physicians used more problem-focused strategies than nurses, while nurses used more emotion-focused strategies. It remains unclear whether the WCQ can cover the specific coping behaviors that are relevant to the current pandemic. This concern is supported by previous studies showing that some of the WCQ items seem to measure behavior that is irrelevant for coping with specific stressors (Ben-Porath et al., 1991; Stone et al., 1991). The unstable factor structure of the WCQ (Edwards \& O'Neill, 1998; Parker et al., 1993) complicates comparisons between countries, which are particularly needed during a global pandemic. 
Other less well established coping measures have been used during a pandemic, including the Simplified Coping Style Questionnaire (SCSQ; Xie, 1998), the Cognitive Emotion Regulation Questionnaire (CERQ; Garnefski et al., 2001), and the Coping Inventory for Stressful Situations (CISS; Endler \& Parker, 1990, 1999). The 20-item SCSQ (Xie, 1998) assesses coping with daily life stressors. Passive coping was associated with greater distress (Nie et al., 2020; Wang et al., 2020; Yu et al., 2020), while active coping was associated with resilience (Lin et al., 2020) during the COVID-19 pandemic. However, apart from a first validation study (Xie, 1998), no study systematically examined the psychometric properties of the SCSQ.

The 36-item Cognitive Emotion Regulation Questionnaire (CERQ; Garnefski et al., 2001) and its 18-item short form (CERQ-short; Garnefski \& Kraaij, 2006) measure cognitive emotion regulation strategies. Both measures have shown good psychometric properties (Garnefski \& Kraaij, 2006; Ireland et al., 2017). The CERQ has been used during the COVID-19 pandemic. Maladaptive cognitive emotion regulation strategies were related to depression, anxiety, and distress (Dubey et al., 2020) and mental health problems (Riaz et al., 2021). However, Dubey et al. (2020) found several unexpected associations between adaptive coping strategies, such as acceptance, and higher levels of depression and distress. These results might indicate that coping strategies that are adaptive in non-pandemic contexts might be not adaptive during a pandemic (Dubey et al., 2020). The CERQ covers cognitive coping (Garnefski \& Kraaij, 2007), but does not consider behavioral and emotional coping. However, behavioral coping seems particularly important during a pandemic or epidemic, such as following governmental recommendations of distance keeping.

The 48-item Coping Inventory for Stressful Situations (CISS; Endler \& Parker, 1990, 1999) and its short 21-item version (CISS-SF; Endler \& Parker, 1994; Endler \& Parker, 1999) have been used in a few studies during the current pandemic. The CISS measures task-, emotion- and avoidance-oriented coping. Reliability and validity have been established (Cohan et al., 2006; McWilliams et al., 2003). Findings demonstrated associations between task-oriented coping and reduced burnout symptoms (Di Monte et al., 2020). Rogowska et al. (2020) reported an unexpected positive association between task-oriented coping and symptoms of anxiety. The authors assumed this unexpected result to be pandemic-specific since the behaviors to cope with everyday stressors might be useless in times of COVID-19 when the situation cannot be changed and might lead to frustration rather than well-being (Rogowska et al., 2020).

In sum, several coping measures exist of which some have been used to investigate coping during the current COVID-19 pandemic. The COPE and the WCQ have been rarely applied during the current pandemic, as they include many items which are difficult to be applied online. The BRIEF-COPE, SCSQ, CERQ, CISS have been used during the COVID-I9 pandemic. While the findings of these studies indicate relationships between coping and wellbeing (Dawson \& GolijaniMoghaddam, 2020; Zacher \& Rudolph, 2021), distress (Dawson \& Golijani-Moghaddam, 2020; Yang et al., 2020), anxiety (Mariani et al., 2020; Mohammadzadeh et al., 2020), and depression (Dubey et al., 2020; Mariani et al., 2020), these measures lack to capture the full range of the coping behavior that is specific for a pandemic, as these measures have been designed to assess coping with everyday stressors. Several studies reported unexpected findings that might be explained by the specific context of a pandemic (Dubey et al., 2020; Rogowska et al., 2020; Zacher \& Rudolph, 2021). Consequently, several researchers have stressed the need to cover the coping behaviors that are unique for a pandemic or an epidemic (Rahman et al., 2020), particularly coping with the stressors related to physical distancing (Cauberghe et al., 2020), which is not covered by the existing measures. To better understand how people are coping with the current pandemic and how coping affects mental health, a brief, valid and reliable measure of coping behavior during a pandemic is required. Therefore, this study aimed to assess the factorial validity and reliability of the Pandemic Coping Scale, a new brief measure of coping in response to the stressors of a pandemic.

\section{Methods}

\section{Study design}

For this psychometric study, cross-sectional data was drawn from the first wave of a longitudinal cohort study on stressors, coping, and symptoms of adjustment disorder during the COVID-19 pandemic (Lotzin et al., 2020). Ethics approval was provided by the Local Psychological Ethics Committee at the Center for Psychosocial Medicine (LPEK) at University Medical Center Hamburg-Eppendorf (LPEK-0149). All participants provided informed consent before participating. The longitudinal cohort study was registered in a study registry (https://doi.org/10.17605/OSF.IO/8XHYG) before the start of the study. All methods were performed in accordance with relevant guidelines and regulations for survey research (Kelley et al., 2003). The data were assessed between June and September 2020.

\section{Sample and Procedure}

Data were collected from German participants. Eligibility criteria were (1) age of at least 18 years, and (2) ability to understand the German language. The trial was actively promoted via the internet (e.g., eBay advertisements, Facebook, interest groups), leisure and sports clubs, large companies, and clubs of senior citizens. After being informed about the study and willing to participate, participants filled out an online questionnaire. A total of $\mathrm{N}=2,316$ participants agreed to take part in the survey and filled out the questions of the Pandemic Coping Scale (PCS).

\section{Measure}

The Pandemic Coping Scale (PCS) was designed as a brief self-report measure to assess coping behavior to the stressors of a pandemic. The coping theory of Folkman et al. (1986) was used as a conceptual framework. In this context, coping is defined as "the person's constantly changing cognitive and behavioral efforts to manage specific external or internal demands that are appraised as taxing or exceeding the person's resources" (Folkman et al., 1986). The first set of items was constructed by reviewing the literature on measures of coping with stressors, as well as on published recommendations on how to cope with the COVID-19 pandemic (American Medical Association, 2020; Center for the Study of Traumatic Stress, 2020; Centers for Disease Control and Prevention, 2020; World Health Organization, 2020). The following six domains of coping behavior relevant for a pandemic or epidemic were identified: preventive adherence (e.g., following the recommendations to limit the spread of the coronavirus); health lifestyle (e.g., paying attention to a healthy diet); rest (e.g., taking breaks); meaningful activities (e.g., doing something enjoyable); daily structure (e.g., maintain a daily routine.); and social support (e.g., spending a good time with 
loved ones, friends, or pet). The first set of items were constructed by a clinical psychologist (first author). Items were then reviewed and refined by consensus of an expert group of professionals in the field of traumatic stress, which were members of the European Society of Traumatic Stress Studies (Lotzin et al., 2020). The resulting first version of the PCS included thirteen four-point items representing coping behaviors in the six identified domains. The items range from 0 to 3 ( 0 = 'I have not been doing this at all'; 1 = 'I've been doing this a little bit'; 2 = 'I've been doing this a medium amount'; $3=$ 'I've been doing this a lot'). The scaling of the items was harmonized with the scaling of the Brief-COPE so that the PCS can be used in addition to this established measure to cover coping behavior that is specific for a pandemic. Higher scores indicate doing more of the respective behavior. Completion of the questionnaire requires about five minutes. Sociodemographic characteristics were also assessed by self-constructed items (e.g., gender, age, education, household income).

\section{Data Analysis}

The psychometric properties of the PCS were evaluated in two analyses. The first study investigated the dimensional structure of the PCS by exploratory factor analysis (EFA). In a second study, it was examined whether the identified dimensions could be replicated by using confirmatory factor analysis (CFA). The two studies were conducted with two different samples, obtained by a random split of the dataset of $\mathrm{N}=2,316$ participants by using the random generator of SPSS 22.0 .

\section{Study 1: Exploratory Factor Analysis}

A sample of $n=1,144$ participants was used for study 1. The EFA was done following current recommendations on conducting EFA (Samuels, 2017). Before conducting the EFA, the bivariate correlation matrix of all PCS items was computed and inspected to detect problems with multicollinearity. The strength of correlations was determined based on Cohen's criteria (Cohen, 1988): low: $r= \pm .10$ to .29 , moderate: $r= \pm .30$ to .49 , large: $r= \pm .50$ to 1.0 . Bivariate correlations of greater than .80 were assumed to indicate multicollinearity problems. For correlations $>.80$, one of the two items was removed.

Scales were extracted based on an EFA using Maximum Likelihood as the extraction method, as this method is recommended when measures are developed to be used with other datasets in the future (Field, 2013, pp. 674-675). An oblimin rotation with Kaiser normalization was applied. Items with communalities of less than .20 were removed, and the EFA was re-run. The optimal number of factors was determined by the following criteria: (1) Kaiser's criterion (eigenvalue > 1); (2) a solution of a maximum number of factors with at least two items with a loading greater than .40 and a low cross-loading. Items with factor loadings $<.30$ and/or cross-loadings $>75 \%$ were removed, starting with the one with the lowest absolute maximum loading on all the factors. The analyses were conducted in SPSS 22.0.

\section{Study 2: Confirmatory Factor Analysis}

A sample of $n=1,172$ participants was used to conduct a CFA to test the factorial validity of the factor model obtained by the EFA in study 1 . The analyses were conducted in SPSS 22.0 and AMOS. Based on the results of the EFA, two models were tested. Model 1 consisted of the 13 items as indicators for four latent factors (Figure 1). Correlations between factors were expected and allowed. To examine whether all factors load on one general factor, Model 1 was extended in Model 2 by adding a second-order general factor on which the four first-order factors loaded (Figure 2).

A CFA using the Maximum Likelihood (ML) estimation method was applied. Normal distribution of the items as a prerequisite for ML estimations was evaluated using the skew- $\left(\gamma_{1}\right)$ and kurtosis index $\left(\gamma_{2}\right) \cdot\left|\gamma_{1}\right| \geq 3.0$ and $\left|\gamma_{2}\right| \geq 10.0$ were considered as problematic (Kline, 2015, p. 76-77). The Variance Inflation Factor (VIF) was calculated to check for multicollinearity between indicators. A VIF $\geq 10.0$ was considered as an indication of multicollinearity (Kline, 2015, p. 72).

Global Goodness of Fit. Based on the recommendations of Schermelleh-Engel et al. (2003), the following cut-offs and indices were used for model evaluation: $\chi^{2}$ statistics and normed $\chi^{2}\left(\chi^{2} / \mathrm{df}\right): \leq 3$ acceptable, $\leq 2$ good; Root Mean Square Error of Approximation (RMSEA): $\leq .08$ acceptable, $\leq .05$ good; Standardized Root Mean Residual (SRMR): $\leq .10$ acceptable, $\leq .05$ good. The Tucker Lewis Index (TLI) and Comparative Fit Index (CFI): > 92 acceptable, according to the recommendations of Hair et al. (2019), taking the large sample size and model complexity into account.

Local Goodness of Fit. Local fit indices were used to assess how reliable the indicators measured the latent constructs. Factor loadings of $\lambda \geq .50$ were rated as moderate, loadings of $\lambda \geq .70$ were rated as large (Hair et al., 2019). The Critical Ratio (C.R.) of $\geq|1.96|$ was used to assess their statistical significance. Factor communalities were considered acceptable with $\lambda^{2} \geq .50$ (Hair et al., 2019).

On the level of the factors, factor reliabilities (FR) were computed, with FR > .60 assumed as sufficient (Bagozzi \& Yi, 1988). Discriminant validity was determined using the Fornell-Larcker criterion that compares the Average Variance Extracted (AVE) with the coefficient of determination (AVE > $\mathrm{R}^{2}$ of two factors; Fornell \& Larcker, 1981).

Additional test quality criteria. The item difficulties were calculated by the mean of the items divided by the maximum item score (assumed as good if $.20 \leq P$ $\leq .80$; Kline, 2013). The corrected item-total correlations were estimated as a measure of item discrimination $\left(r_{i t} \geq .30\right.$ rated as acceptable and $r_{i t} \geq .50$ as good; Krohne \& Hock, 2015, p. 52). The internal consistency was computed using Cronbach's a for the subscales and the total scale.

Model comparison. A chi-square difference test was applied to compare the fit of Model 1 and Model $2\left(\Delta \chi^{2}=\chi^{2}\right.$ Model $2-\chi^{2}$ Model 1 and $\Delta \mathrm{df}=\mathrm{df}{ }_{\text {Model } 2}-\mathrm{df}$ Model 1 ; Kline, 2015, p. 281). Because chi-square tests tend to be oversensitive in large samples (Hair, 2019), a conservative significance level of a $=.01$ was chosen.

\section{Results}




\section{Study 1}

\section{Sample characteristics.}

The sample included $n=1,144$ cases of German adults from the general public (Table 1). The sample can be characterized as a medium to high-educated sample with varying ages and incomes. Ages ranged between 18 and 82 years, with a mean age of $41.17(S D=12.79)$. More participants were female $(n=$ $811,70.9 \%)$ than male $(n=327,28.6 \%)$, or of diverse gender $(n=6,0.52 \%)$. Only few participants $(n=4,0.35 \%)$ reported less than ten years of schooling; $12.8 \%(n=146)$ completed up to thirteen years of schooling as highest education; $35.1 \%(n=402)$ completed vocational training; $48.2 \%$ ( $n=551)$ graduated university; and 3.58\% $(n=41)$ completed a doctorate. One-fifth of the sample $(n=251,21.9 \%)$ classified themselves as being at risk for severe or lifethreatening symptoms of COVID-19. One fifth $(n=268,23.4 \%)$ stated to have been diagnosed with a mental disorder, of which $8.0 \%(n=92)$ reported being affected by a mental disorder at the time of the assessment.

\section{Exploratory Factor Analysis}

Intercorrelations ranged from -.001 to .76. As no correlation exceeded the threshold of .80 , all items were retained in the analysis. The communalities of the initial solution were greater than .20 for all items, indicating that all items could be used. The means, standard deviations, and indices for skewness and kurtosis for the items are shown in Table 2. All items were approximately normally distributed, although some items showed negative skew. No indication of multicollinearity between the indicators was found (all VIF $<10.0$ ).

The results of the EFA suggested a four-factor solution (Table 2). The factor solution was also confirmed by visual examination of the scree plot. No additional factor exceeded the threshold of an Eigenvalue of 1.0. All items had loadings > .40 on the respective factor. The four factors were named (1) 'Healthy Lifestyle', (2) 'Joyful Activities', (3) 'Daily Structure', and (4) 'Prevention Adherence'. The factors accounted for 25.2\% (Daily Structure), 10.8\% (Healthy Lifestyle), 4.3\% (Joyful Activities), and 4.4\% (Prevention Adherence) of the total variance, respectively. The factor correlations ranged from $r=.20$ (Joyful Activities with Prevention Adherence) to $r=.58$ (Healthy Lifestyle with Joyful Activities). In the four-factor solution, each item had a salient loading on only one factor. No item of the rotated factor matrix cross-loaded more than $75 \%$ on another factor. The factor loadings of the 13 items ranged between .39 and .94, suggesting meaningful and practically significant factor loadings (Cudeck \& O’Dell, 1994).

Of the six pandemic coping domains that were specified before the analysis (please see Measure section), the domains 'Healthy Lifestyle', 'Daily Structure', and 'Prevention Adherence' were identified as single factors in the EFA. The two previously specified domains 'Meaningful Activities' and 'Social Activities' loaded on one common factor, which was named 'Joyful Activities'. The two items of the previously specified domain 'Resting' loaded on the 'Healthy Lifestyle' factor.

\section{Study 2}

\section{Sample characteristics.}

Study 2 included $n=1,172$ German adults (Table 1). The sample characteristics were similar to those of the sample of study 1 and can be characterized as a medium to high-educated sample with varying ages and income. The mean age was $41.19(S D=13.1)$, which ranged from 18 to 80 years. The majority of the sample was female $(n=813,69.4 \%)$, the remaining participants were male $(n=355,30.3 \%)$ or of diverse gender $(n=4,0.3 \%)$. Only $0.3 \%(n=3)$ of the sample completed less than nine years of schooling. The remaining participants completed up to thirteen years of schooling $(n=138,11.8 \%)$, passed a vocational training $(n=416,35.5 \%)$, graduated from university $(n=572,48.8 \%)$ or completed a doctorate $(n=43,3.7 \%)$. One-fifth of the sample ( $n=253,21.6 \%)$ classified themselves as being at risk for severe or life-threatening symptoms of the coronavirus disease. 23.2\% ( $n=272)$ reported being diagnosed with a mental disorder; and $8.0 \%(n=94)$ stated to be currently affected by a mental disorder.

\section{Confirmatory Factor Analysis}

All indicators were approximately normally distributed (skew index $\left|\gamma_{1}\right|<3.0$ and kurtosis index $\left|\gamma_{2}\right|<10.0$; Supplement 1; Kline, 2015, p. 76-77). There was no indication of multicollinearity between the indicators (VIF $<10.0$, Kline, 2015, p. 72).

\section{Model 1.}

Global Goodness of Fit. The $\chi^{2}$ statistics suggested a discrepancy between the theoretical model and the model implied by the observed data $\left(\chi^{2}(59, N=\right.$ $1,172)=367.0, p<.001$, normed $\chi^{2}=6.22$, Table 3 ). The RMSEA showed an acceptable fit (RMSA $=.067, p<.001,90 \% \mathrm{Cl}=.060, .073$ ), the SRMR indicated a good fit (SRMR $=.043)$, the CFI (.926) showed an acceptable fit. However, the TLI (.902) indicated an insufficient model fit as it was lower than .92.

Local Goodness of Fit. Factor loadings were moderate $(\lambda \geq .50)$ to large $(\lambda \geq .70)$, apart from smaller loadings of three indicators of the factor 'Joyful Activities' (Supplement 2). All factor loadings were significant (C.R. $\geq|1.96|$ ). Only four indicators showed communalities $\lambda^{2} \geq .50$ (items $5,6,10$, and 11 ; Supplement 2). The factors mainly showed discriminant validity in terms of a small to medium correlation (ranging from .05 to .33, Supplement 3 ) except for 'Healthy Lifestyle' and 'Joyful Activities', which showed a medium correlation ( $r=.54)$. Factor reliability was considered as good with FR > .60 for all factors except for 'Prevention Adherence' (FR = .52, Supplement 3).

Additional test quality criteria. Item difficulties were considered as good (Supplement 4), except for the indicators of 'Prevention Adherence' which showed a low difficulty $(P>.80)$. Item discrimination indices were good $\left(r_{i t}>.50\right)$ or acceptable $\left(r_{i t}>.30\right)$. Internal consistency was excellent for the factor 'Daily Structure' $(a=.86)$, and moderate for the factor 'Healthy Lifestyle' $(a=.79)$. The factors 'Joyful Activities' $(a=.60)$ and 'Prevention Adherence' $(a=.51)$ showed low internal consistency. 


\section{Model 2.}

Overall, the global and local fit indices and the test quality criteria of Model 2 were similar to those found in Model 1.

Global Goodness of Fit. The $\chi^{2}$ statistic referred to a statistically significant difference between the specific and observed variance-covariance matrix ( $\chi^{2}(61, N$ $=1172)=373.33, p<.001$, normed $\chi^{2}=6.12$; Table 3$)$. The RMSEA showed an acceptable fit (RMSEA $\left.=.066, p<.001,90 \% \mathrm{Cl}=.060, .073\right)$, the SRMR showed a good fit (SRMR $=.043)$. While the CFI $(.925)$ indicated an acceptable model fit, the TLI (.904) indicated an insufficient fit, as it was $<.92$.

Local Goodness of Fit. Factor loadings of the indicators were moderate to large, except for items 8 and 12 of the factor 'Joyful Activities' (Supplement 2). The factor loadings on the second-order general factor (named 'Pandemic Coping') were large for 'Healthy Lifestyle' $(\lambda=.87)$ and 'Joyful Activities' ( $\lambda=.85$ ), moderate for 'Daily Structure' $(\lambda=.67)$ and small for 'Prevention Adherence' $(\lambda=.36$, Supplement 2$)$. All factor loadings were significant (C.R. $\geq|1.96|)$. Consistent with Model 1, communalities $\lambda^{2} \geq .50$ were only found for items $5,6,10$, and 11 (Supplement 2). The factor reliabilities could be considered as good for the second-order general factor 'Pandemic Coping' ( $F R=.90)$ and for all first-order factors $(F R>.60)$ except for 'Prevention Adherence' (FR $=.52$, Supplement 3).

Additional test quality criteria. Item difficulties were evaluated as good for all indicators (Supplement 4) except for the indicators of 'Prevention Adherence', which showed low difficulties $(P>.80)$. Item discrimination indices concerning the second-order general factor 'Pandemic Coping' were evaluated as good $\left(r_{i t}>\right.$ $.50)$ or acceptable $\left(r_{i t}>.30\right)$, except for the indicators of 'Prevention Adherence'. The internal consistency of the second-order general factor 'Pandemic Coping' was acceptable $(a=.83)$. For the internal consistencies of the subscales, please see the result section for Model 1.

Model comparison. The chi-square difference test comparing Model 1 and Model 2 showed no significant difference in their fit to the data $\left(\Delta \chi^{2}(2, N=1172)=\right.$ $6.36, p=.042)$.

\section{Discussion}

Coping with the specific stressors of a pandemic may impact physical and psychological health and well-being. This research aimed to assess the factorial validity and reliability of the Pandemic Coping Scale (PCS), a brief measure of coping with the stressors of a pandemic. In a first study, we identified factors of the PCS by using exploratory factor analysis (EFA) in a German sample. In a second study, we examined whether the factor structure identified in study 1 could be replicated in a second German sample using confirmatory factor analysis (CFA). In study 2, we assessed the global goodness of fit of the factor structure, the local goodness of, fit and test quality criteria, which were evaluated in two models: a four-factor model, and a four-factor model combined with a second-order general factor.

\section{Exploratory Factor Analysis}

The EFA conducted in study 1 indicated a four-factor solution which accounted for $44.6 \%$ of the total variance. Each of the 13 items showed salient and significant factor loadings on only one of the four factors. Based on the meaning of the included items, the four factors were named 'Healthy Lifestyle', Joyful Activities', 'Daily Structure,' and 'Prevention Adherence'.

\section{Confirmatory Factor Analysis}

\section{Global Fit.}

The four-factor solution could be replicated in study 2 by applying CFA. Most of the global fit indices (RMSEA, SRMR, CFI) showed a sufficient fit in a model with four separate factors, as well as in a model which additionally included a second-order general factor. The $\chi^{2}$ statistics of both models indicated a deviation from the observed model, consistent with earlier research showing that the $\chi^{2}$ test tends to be oversensitive in large samples (Hair et al., 2019). The comparison of the two models (four-factor model vs. a four-factor model combined with a second-order general factor) showed no difference in their fit to the data. These results indicate that a second-order general factor seems to be consistent with the data structure and may legitimize the calculation of a total score of the 'Pandemic Coping Scale'.

\section{Local Fit.}

On the level of the indicators, we found that most of the factor loadings of the two tested factor models were moderate to large, except for some items of the subscale 'Joyful Activities'. The factor loading of the items of the subscale 'Prevention Adherence' on the second-order general factor was also lower. The subscale 'Joyful Activities' was initially constructed as two separate domains, but according to our results of the EFA, the constructs of meaningful and social activities overlapped. However, these two domains may still cover separate aspects resulting in increased heterogeneity of the combined scale. This might explain the comparably small factor loadings of the items on 'Joyful Activities', but greater factor loadings on the second-order general factor.

On the level of the factors, we found good factor reliabilities for all first-order factors except for 'Prevention Adherence' for both models. Therefore, the indicators within each factor share a sufficient amount of variance indicating that they measure a similar construct. Most factors showed evidence for discriminant validity, indicating that the items of the subscales represent distinct constructs. These findings are in line with the results of study 1 , showing that all items primarily loaded on only one factor. The subscales 'Healthy Lifestyle' and 'Joyful Activities' shared variance with each other, indicating that they were not fully independent.

Item Difficulty. Our analysis of additional test quality criteria yielded comparable results for both tested factor models for most of the assessed indices. The items of the three subscales showed good item difficulties, whereas the items of 'Prevention Adherence' were comparably easy in both models. Consequently, 
this subscale may not perfectly discriminate between people with very high versus high prevention adherence scores. The scale might benefit from additional items with varying difficulties. However, the data assessment for this study took place three to six months after the start of the pandemic. It has become evident that people - after the lockdown has become an enduring condition - are less adherent to the lockdown measures. The reduced prevention adherence behavior which is measured by the subscale is likely to increase the item variance and item difficulty. Future studies using the PCS in the later phases of the pandemic are needed to further examine the item difficulties of this subscale.

Item Discrimination and Internal Consistency. Acceptable indices for item discrimination were found for all items, with one exception: The items of the subscale 'Prevention Adherence' did not sufficiently discriminate between high and low scores in the second-order general factor in Model 2. Internal consistency was excellent for 'Daily Structure', acceptable for 'Healthy Lifestyle', but low for Joyful Activities' and 'Prevention Adherence'. Cronbach's a increases with an increasing number of items per scale (Ponterotto \& Ruckdeschel, 2007); the low number of indicators of the factor 'Prevention Adherence' might have contributed to the low internal consistency. Furthermore, calculations of Cronbach's a are affected by the total item variance (Streiner, 2003). The low difficulties of both items of this scale may have restricted the item variance, which could have contributed to the low internal consistency of the factor 'Prevention Adherence'. The lower internal consistency of 'Joyful Activities' might be attributable to the heterogeneity caused by the inclusion of two formerly separate domains.

Overall, the findings of both studies support the factorial validity and reliability of the Pandemic Coping Scale (PCS). However, compared with the other subscales, the subscale 'Prevention Adherence' showed lower factor reliability and a lower factor loading on the second-order general factor, lower item discrimination indices concerning the second-order general factor, lower internal consistency, and lower item difficulties. The lower factorial validity and reliability might be explained by a reduced item variance. Most of the conducted calculations are based on variance-covariance matrices; reduced item variance, therefore, results in lower local and lower global model fit. Alternatively, the items of this subscale might measure content that is less related to the content domains of the other three subscales. While the subscale of 'Prevention Adherence' includes behavior such as informing oneself about the pandemic situation and following the recommendations, the other three subscales of the PCS focus on self-care and social contacts. This could explain the smaller factor loading of 'Prevention Adherence' and moderate to large factor loadings of the remaining subscales on the second-order general factor. It would also explain why the items of 'Prevention Adherence' could distinguish between participants with high and low scores in 'Prevention Adherence' but could not distinguish sufficiently between participants with high and low scores in the total score of the PCS. Removing the subscale of 'Prevention Adherence' might therefore result in a higher internal consistency of the total score of 'Pandemic Coping' and would increase the homogeneity of the items. The elimination of both items could improve local and global model fit, as the two items showed reduced item variance. However, the removal of this subscale carries the risk of leaving out an important area of coping behavior that is specific for a pandemic. Alternatively, additional items measuring preventive adherence to the PCS with higher item difficulties could be added to the scale.

\section{Strength and Limitations}

This study has strengths and limitations. A strength of this study is the use of sufficiently sized samples, and the combined use of EFA and CFA in two randomized splits of a large sample to replicate the results obtained in EFA. A limitation is that the sample was not representative of the German general population concerning gender, income, and education. The study is also limited by the use of self-report questionnaires that might have led to different results compared to observational measures of coping. Finally, validity testing of a measure needs to demonstrate not only factorial validity and reliability but also convergent and discriminant validity. We did not examine the convergent and discriminant validity of the PCS in this study.

\section{Future directions}

Future studies need to examine the psychometric properties of the PCS among a representative sample, as well as the measure's convergent and discriminant validity with other coping measures. The psychometric properties of the questionnaire might be further improved by adding items to the Prevention Adherence subscale and examining its factorial validity and reliability. The strength and direction of association of the PCS with other measures of coping during a pandemic, or with measures of coping with daily life stressors should be examined. Finally, the appropriateness of the usage of the measure should be also examined in other countries.

\section{Conclusion}

Overall, the findings of both studies show empirical support for the factorial validity and reliability of the Pandemic Coping Scale. The subscale 'Prevention Adherence' might benefit from further adaption and evaluation.

\section{Declarations}

\section{Ethics approval and consent to participate}

Ethics approval was provided by the Local Psychological Ethics Committee at the Center for Psychosocial Medicine (LPEK) at University Medical Center Hamburg-Eppendorf (LPEK-0149). All participants provided informed consent before participating. The longitudinal cohort study was registered in a study registry (https://doi.org/10.17605/OSF.IO/8XHYG) before the start of the study.

\section{Consent for publication}

“Not applicable” 
Data supporting the findings of this study will be available upon reasonable request from the first author.

\section{Competing interests}

The authors declare to have no interests that affect the data analysis, reporting of results, and interpretation.

\section{Funding}

This study received no funding.

\section{Authors' contributions}

AL designed and coordinated the study, drafted the manuscript, and carried out the EFA; RK carried out the CFA and contributed to the writing of the manuscript; SB contributed to the data management and reviewed the manuscript; MB contributed to the recruitment. LK, AO, MB, and IS reviewed the manuscript. All authors read and approved the final manuscript.

\section{Acknowledgments}

We greatly thank the study team, in particular, Laura Kenntemich for the data management, and Eike Neumann-Runde for his technical support in the setup of the survey. The authors thank the ESTSS COVID-19 study consortium (please see https://doi.org/10.17605/OSF.IO/8XHYG) for reviewing the PCS items.

\section{References}

1. American Medical Association (2020, April 24). Managing mental health during COVID-19. Chicago, IL: American Medical Association. https://www.amaassn.org/delivering-care/public-health/managing-mental-health-during-covid-19

2. Bagozzi, R. P., \& Yi, Y. (1988). On the evaluation of structural equation models. Journal of the Academy of Marketing Science, $16(1), 74-94$. http://dx.doi.org/10.1007/BF02723327

3. Bäuerle, A., Teufel, M., Musche, V., Weismüller, B., Kohler, H., Hetkamp, M., Dörrie, N., Schweda, A., \& Skoda, E.-M. (2020). Increased generalized anxiety, depression and distress during the COVID-19 pandemic: A cross-sectional study in Germany. Journal of Public Health, 42(4), $672-678$.

https://doi.org.de/10.1093/pubmed/fdaa106

4. Ben-Porath, J. S., Waller, N. G., \& Butcher, J. N. (1991). Assessment of Coping: An Empirical Illustration of the Problem of Inapplicable Items. Journal of Personality Assessment, 57(1), 162-176. https://doi.org/10.1207/s15327752jpa5701_18

5. Carver, C. S. (1997). You want to measure coping but your protocol'too long: Consider the brief COPE. International Journal of Behavioral Medicine, 4(1), 92.

6. Carver, C. S., Scheier, M. F., \& Weintraub, J. K. (1989). Assessing coping strategies: A theoretically based approach. Journal of Personality and Social Psychology, 56(2), 267-283. https://doi.org/10.1037/0022-3514.56.2.267

7. Cauberghe, V., Van Wesenbeeck, I., De Jans, S., Hudders, L., \& Ponnet, K. (2020). How adolescents use social media to cope with feelings of loneliness and anxiety during COVID-19 lockdown. Cyberpsychology, Behavior, and Social Networking, cyber.2020.0478. https://doi.org/10.1089/cyber.2020.0478

8. Center for the Study of Traumatic Stress. (2020). Sustaining the well-being of healthcare personnel during coronavirus and other infectious disease outbreaks. Bethesda, MD: Department of Psychiatry, Uniformed Services University. https://www.cstsonline.org/assets/media/documents/CSTS_FS_Sustaining_WellBeing_of_Healthcare_Personnel_during_Infectious_Disease_Outbreaks.pı

9. Centers for Disease Control and Prevention (CDC). (2020, April 30). Coronavirus Disease 2019 (COVID-19): Stress and coping. Atlanta, GA: U.S. Department of Health \& Human Services. https://www.cdc.gov/coronavirus/2019-ncov/daily-life-coping/managing-stress-anxiety.html

10. Cohan, S. L., Jang, K. L., \& Stein, M. B. (2006). Confirmatory factor analysis of a short form of the Coping Inventory for Stressful Situations. Journal of Clinical Psychology, 62(3), 273-283. https://doi.org/10.1002/jclp.20211

11. Cohen, J. (1988). Statistical power analysis for the behavioral sciences. L. Erlbaum Associates.

12. Cudeck, R., \& O’Dell, L. L. (1994). Applications of standard error estimates in unrestricted factor analysis: Significance tests for factor loadings and correlations. Psychological Bulletin, 115(3), 475. https://doi.org/10.1037/0033-2909.115.3.475.

13. Dawson, D. L., \& Golijani-Moghaddam, N. (2020). COVID-19: Psychological flexibility, coping, mental health, and wellbeing in the UK during the pandemic. Journal of Contextual Behavioral Science, 17, 126-134. https://doi.org/10.1016/j.jcbs.2020.07.010

14. Di Monte, C., Monaco, S., Mariani, R., \& Di Trani, M. (2020). From resilience to burnout: Psychological features of Italian general practitioners during COVID-19 emergency. Frontiers in Psychology, 11, 567201. https://doi.org/10.3389/fpsyg.2020.567201

15. Dubey, N., Podder, P., \& Pandey, D. (2020). Knowledge of COVID-19 and its influence on mindfulness, cognitive emotion regulation and psychological flexibility in the Indian Community. Frontiers in Psychology, 11, 589365. https://doi.org/10.3389/ fpsyg.2020.589365

16. Edwards, J. R., \& O’Neill, R. M. (1998). The Construct Validity of Scores on the Ways of Coping Questionnaire: Confirmatory analysis of alternative factor structures. Educational and Psychological Measurement, 58(6), 955-983. https://doi.org/10.1177/ 0013164498058006007

17. Endler, Norman S., \& Parker, J. D. A. (1994). Assessment of multidimensional coping: Task, emotion, and avoidance strategies. Psychological Assessment, 6(1), 50-60. https://doi.org/10.1037/1040-3590.6.1.50

18. Endler, N.S., \& Parker, J. D. A. (1990). Coping Inventory for Stressful Situations (CISS): Manual. Multi-Health Systems.

19. Endler, N.S., \& Parker, J. D. A. (1999). Coping Inventory for Stressful Situations (CISS): Manual (2nd ed.). Multi-Health Systems. 
20. Field, A. (2013). Discovering statistics using IBM SPSS Statistics. London: SAGE.

21. Fiorillo, A., Sampogna, G., Giallonardo, V., Del Vecchio, V., Luciano, M., Albert, U., Carmassi, C., Carrà, G., Cirulli, F., Dell'Osso, B., Nanni, M. G., Pompili, M., Sani, G., Tortorella, A., \& Volpe, U. (2020). Effects of the lockdown on the mental health of the general population during the COVID-19 pandemic in Italy: Results from the COMET collaborative network. European Psychiatry: The Journal of the Association of European Psychiatrists, 63(1), e87-e87. https://doi.org/10.1192/j.eurpsy.2020.89

22. Folkman, S., Lazarus, R. S., Dunkel-Schetter, C., DeLongis, A., \& Gruen, R. J. (1986). Dynamics of a stressful encounter: Cognitive appraisal, coping, and encounter outcomes. Journal of Personality and Social Psychology, 50(5), 992. https://doi.org/10.1037/0022-3514.50.5.992

23. Folkman, Susan., \& Lazarus, R. S. (1988). Manual for the ways of coping questionnaire. Consulting Psychologists Press; /z-wcorg/.

24. Fornell, C., \& Larcker, D. F. (1981). Evaluating structural equation models with unobservable variables and measurement error. Journal of Marketing Research, 18(1), 39-50. https://doi.org/10.1177/002224378101800104

25. Fullana, M. A., Hidalgo-Mazzei, D., Vieta, E., \& Radua, J. (2020). Coping behaviors associated with decreased anxiety and depressive symptoms during the COVID-19 pandemic and lockdown. Journal of Affective Disorders, 275, 80-81. https://doi.org/10.1016/j.jad.2020.06.027

26. Garnefski, N. \& Kraaij., V. (2007). The Cognitive Emotion Regulation Questionnaire. European Journal of Psychological Assessment, $23(3), 141-149$. https://doi.org/10.1027/1015-5759.23.3.141

27. Garnefski, Kraaij, V., \& Spinhoven, P. (2001). Negative life events, cognitive emotion regulation and emotional problems. Personality and Individual Differences, 30(8), 1311-1327. https://doi.org/10.1016/S0191-8869(00)00113-6

28. Garnefski, N., \& Kraaij, V. (2006). Cognitive Emotion Regulation Questionnaire: Development of a short 18-item version (CERQ-short). Personality and Individual Differences, 41, 1045-1053. https://doi.org/10.1016/j.paid.2006.04.010

29. Hair, J. F. (2010). Multivariate data analysis. Prentice Hall.

30. Hair J. F., Black, W. C., Babin, B. J., \& Anderson, R. E. (2019). Multivariate data analysis (8th ed.). Cengage Learning EMEA.

31. Ireland, M. J., Clough, B. A., \& Day, J. J. (2017). The cognitive emotion regulation questionnaire: Factorial, convergent, and criterion validity analyses of the full and short versions. Personality and Individual Differences, 110, 90-95. https://doi.org/10.1016/ j.paid.2017.01.035

32. Kalaitzaki, A. (2020). Positive and negative mental health outcomes and internal resources among the general population in Greece: A nation-wide survey amid COVID-19 lockdown [Preprint]. PsyArXiv. https://doi.org/10.31234/osf.io/g29eb

33. Kato, T. (2015). Frequently used coping scales: A meta-analysis. Stress and Health, 31(4), 315-323. https://doi.org/10.1002/smi.2557

34. Kelley, K., Clark, B., Brown, V., \& Sitzia, J. (2003). Good practice in the conduct and reporting of survey research. International Journal for Quality in health care, 15(3), 261-266. https://doi.org/10.1093/intqhc/mzg031

35. Kline, P. (2013). Handbook of Psychological Testing. Routledge.

36. Kline, R. B. (2015). Principles and practice of structural equation modeling (4th ed.). Guilford Press. https://ebookcentral-1 proquest-1 com100f089Ik0117.emedien3.sub.uni-hamburg.de/lib/subhh/reader.action?doclD=4000663

37. Koopmann, A., Georgiadou, E., Kiefer, F., \& Hillemacher, T. (2020). Did the general population in Germany drink more alcohol during the COVID-19 pandemic lockdown? Alcohol and Alcoholism, 55(6), 698-699. https://doi.org/10.1093/alcalc/agaa058

38. Krohne, H. W., Hock, M., Heuer, H., Rösler, F., \& Tack, W. H. (Eds.). (n.d.). Psychologische Diagnostik: Grundlagen und Anwendungsfelder.

39. Lin, J., Ren, Y.-H., Gan, H.-J., Chen, Y., Huang, Y.-F., \& You, X.-M. (2020). Factors associated with resilience among non-local medical workers sent to Wuhan, China during the COVID-19 outbreak. BMC Psychiatry, 20(1), 417. https://doi.org/10.1186/s12888-020-02821-8

40. Lotzin, A., Aakvaag, H., Acquarini, E., Ajdukovic, D., Ardino, V., Böttche, M., Bondjers, K., Bragesjö, M., Dragan, M., Braga, M. M. C. de F. F., Gelezelyte, O., Grajewski, P., Javakhishvili, D., Kazlauskas, E., Knefel, M., Lueger-Schuster, B., Makhashvili, N., Mooren, T., Sales, L., ... Schäfer, I. (2020). Stressors, coping and symptoms of adjustment disorder in the course of COVID-19 pandemic - The European Society for Traumatic Stress Studies (ESTSS) pan-European study. https://doi.org/10.17605/OSF.IO/8XHYG

41. Lundqvist, L.-O., \& Ahlström, G. (2006). Psychometric evaluation of the Ways of Coping Questionnaire as applied to clinical and nonclinical groups. Journal of Psychosomatic Research, 60(5), 485-493. https://doi.org/10.1016/j.jpsychores.2005.08.019

42. Mariani, R., Renzi, A., Di Trani, M., Trabucchi, G., Danskin, K., \& Tambelli, R. (2020). The Impact of Coping Strategies and Perceived Family Support on Depressive and Anxious Symptomatology During the Coronavirus Pandemic (COVID-19) Lockdown. Frontiers in Psychiatry, $11,587724$. https://doi.org/10.3389/fpsyt.2020.587724

43. Mattioli, A. V., Puviani, M. B., Nasi, M., \& Farinetti, A. (2020). COVID-19 pandemic: The effects of quarantine on cardiovascular risk. European Journal of Clinical Nutrition, 74, 852-855. https://doi.org/10.1038/s41430-020-0646-z

44. McWilliams, L. A., Cox, B. J., \& Enns, M. W. (2003). Use of the Coping Inventory for Stressful Situations in a clinically depressed sample: Factor structure, personality correlates, and prediction of distress. Journal of Clinical Psychology, 59(12), 1371-1385. https://doi.org/10.1002/jclp.10228

45. Meyer, J., McDowell, C., Lansing, J., Brower, C., Smith, L., Tully, M., \& Herring, M. (2020). Changes in physical activity and sedentary behavior in response to COVID-19 and their associations with mental health in 3052 US adults. International Journal of Environmental Research and Public Health, $17,6469$. https://doi.org/10.3390/ijerph17186469

46. Mohammadzadeh, F., Delshad Noghabi, A., Khosravan, S., Bazeli, J., Armanmehr, V., \& Paykani, T. (2020). Anxiety severity levels and coping strategies during the COVID-19 pandemic among people aged 15 years and above in Gonabad, Iran. Archives of Iranian Medicine, 23(9), 633-638. https://doi.org/10.34172/aim.2020.76

47. Nie, A., Su, X., Zhang, S., Guan, W., \& Li, J. (2020). Psychological impact of COVID-19 outbreak on frontline nurses: A cross-sectional survey study. Journal of Clinical Nursing, 29(21-22), 4217-4226. https://doi.org/10.1111/jocn.15454

Page $9 / 13$ 
48. Ong, J. L., Lau, T. Y., Massar, S. A. A., Chong, Z. T., Ng, B. K. L., Koek, D., Zhao, W., Yeo, B. T. T., Cheong, K., \& Chee, M. W. L. (2020). COVID-19-related mobility reduction: Heterogenous effects on sleep and physical activity rhythms. Sleep Research Society, zsaa179, 1-13.

https://doi.org/10.1093/sleep/zsaa179

49. Palumbo, R. (2020). Let me go to the office! An investigation into the side effects of working from home on work-life balance. International Journal of Public Sector Management, 33(67), 771-790. https://doi.org/10.1108/IJPSM-06-2020-0150

50. Parker, J. D., Endler, N. S., \& Bagby, R. M. (1993). If it changes, it might be unstable: Examining the factor structure of the Ways of Coping Questionnaire. Psychological Assessment, 5(3), 361-368. https://doi.org/10.1037/1040-3590.5.3.361

51. Ponterotto, J. G., \& Ruckdeschel, D. E. (2007). An overview of coefficient alpha and a reliability matrix for estimating adequacy of internal consistency coefficients with psychological research measures. Perceptual and Motor Skills, 105(3), 997-1014. https://doi.org/10.2466/pms.105.3.997-1014

52. Rahman, H. A., Issa, W. B., \& Naing, L. (2020). Psychometric properties of Brief-COPE inventory among nurses [Preprint]. https://doi.org/10.21203/rs.3.rs$84184 / \mathrm{v} 1$

53. Ramalho, R. (2020). Alcohol consumption and alcohol-related problems during the COVID-19 pandemic: A narrative review. Australasian Psychiatry, 28(5), 524-526. https://doi.org/10.1177/1039856220943024

54. Rexrode, K. R., Petersen, S., \& O'Toole, S. (2008). The Ways of Coping Scale: A reliability generalization study. Educational and Psychological Measurement, 68(2), 262-280. https://doi.org/10.1177/0013164407310128

55. Riaz, M., Abid, M., \& Bano, Z. (2021). Psychological problems in general population during COVID-19 pandemic in Pakistan: Role of cognitive emotion regulation. Annals of Medicine, 53(1), 189-196. https://doi.org/10.1080/07853890.2020.1853216

56. Rogowska, A. M., Kuśnierz, C., \& Bokszczanin, A. (2020). Examining anxiety, life satisfaction, general health, stress and coping styles during the COVID-19 pandemic in Polish sample of university students. Psychology Research and Behavior Management, Volume 13, 797-811.

https://doi.org/10.2147/PRBM.S266511

57. Rubin, O., Nikolaeva, A., Nello-Deakin, S., \& te Brömmelstroet, M. (2020). What can we learn from the COVID-19 pandemic about how people experience working from home and commuting? Centre for Urban Studies, University of Amsterdam. https://urbanstudies.uva.nl/ content/blog-series/covid-19pandemic-working-from-home-and-commuting.html

58. Salopek-Žiha, D., Hlavati, M., Gvozdanović, Z., Gašić, M., Placento, H., Jakić, H., Klapan, D., \& Šimić, H. (2020). Differences in distress and coping with the COVID-19 stressor in nurses and physicians. Psychiatria Danubina, 32(2), 287-293. https://doi.org/10.24869/psyd.2020.287

59. Samuels, P. (2017). Advice on exploratory factor analysis. https://www.researchgate.net/ publication/319165677_Advice_on_Exploratory_Factor_Analysis

60. Schermelleh-Engel, K., Moosbrugger, H., \& Müller, H. (2003). Evaluating the fit of structural equation models: Tests of significance and descriptive Goodness-of-Fit measures. Methods of Psychological Research - Online, 8(2), 23-74.

61. Serafini, G., Parmigiani, B., Amerio, A., Aguglia, A., Sher, L., \& Amore, M. (2020). The psychological impact of COVID-19 on the mental health in the general population. QJM: An International Journal of Medicine, 113(8), 531-537. https://doi.org/10.1093/qjmed/hcaa201

62. Sheroun, D., Wankhar, D. D., Devrani, A., Lissamma, P. V., Gita, S., \& Chatterjee, K. (2020). A study to assess the perceived stress and coping strategies among B. Sc. Nursing students of selected colleges in Pune during COVID-19 pandemic lockdown. International Journal of Science and Healthcare Researc, 5(2), 280-288.

63. Skinner, E. A., \& Zimmer-Gembeck, M. (2016). Coping. In Encyclopedia of Mental Health (2nd ed.), pp. 350-357. Elsevier/Academic Press.

64. Stone, A. A., Greenberg, M. A., Kennedy-Moore, E., \& Newman, M. G. (1991). Self-report, situation-specific coping questionnaires: What are they measuring? Journal of Personality and Social Psychology, 61(4), 648-658. https://doi.org/10.1037/0022-3514.61.4.648

65. Streiner, D. L. (2003). Starting at the beginning: An introduction to coefficient alpha and internal consistency. Journal of Personality Assessment, 80(1), 99-103. https://doi.org/10.1207/S15327752JPA8001_18

66. Taylor, S. E., \& Stanton, A. L. (2007). Coping resources, coping processes, and mental health. Annual Review of Clinical Psychology, 3(1), $377-401$. https://doi.org/10.1146/annurev.clinpsy.3.022806.091520

67. Usher, K., Durkin, J., \& Bhullar, N. (2020). The COVID-19 pandemic and mental health impacts. International Journal of Mental Health Nursing, 29, 315318. https://doi.org/10.1111/inm.12726

68. Wang, H., Xia, Q., Xiong, Z., Li, Z., Xiang, W., Yuan, Y., Liu, Y., \& Li, Z. (2020). The psychological distress and coping styles in the early stages of the 2019 coronavirus disease (COVID-19) epidemic in the general mainland Chinese population: A web-based survey. PLOS ONE, 15(5), e0233410.

https://doi.org/10.1371/journal.pone.0233410

69. World Health Organization (WHO). (2020). Mental health and psychosocial considerations during the COVID-19 outbreak. World Health Organization, Geneva. https://apps.who.int/ iris/bitstream/handle/10665/331490/WHO-2019-nCoV-MentalHealth-2020.1-eng.pdf

70. Xie, Y. (1998). Reliability and validity of the simplified Coping Style Questionnaire. Chinese Journal of Clinical Psychology, 6(2), 114-115.

71. Yang, X., Xiong, Z., Li, Z., Li, X., Xiang, W., Yuan, Y., \& Li, Z. (2020). Perceived psychological stress and associated factors in the early stages of the coronavirus disease 2019 (COVID-19) epidemic: Evidence from the general Chinese population. PLOS ONE, 15(12), e0243605. https://doi.org/10.1371/journal.pone.0243605

72. Yu, H., Li, M., Li, Z., Xiang, W., Yuan, Y., Liu, Y., Li, Z., \& Xiong, Z. (2020). Coping style, social support and psychological distress in the general Chinese population in the early stages of the COVID-19 epidemic. BMC Psychiatry, 20(1), 426. https://doi.org/ 10.1186/s12888-020-02826-3

73. Zacher, H., \& Rudolph, C. W. (2021). Individual differences and changes in subjective wellbeing during the early stages of the COVID-19 pandemic. American Psychologist, 76(1), 50-62. https://doi.org/10.1037/amp0000702 
Tables

Table 1

Sociodemographic Characteristics

\begin{tabular}{|c|c|c|c|c|}
\hline \multirow[b]{2}{*}{ Variable } & \multicolumn{2}{|c|}{ Study $1, \mathrm{n}=1,144$} & \multicolumn{2}{|c|}{ Study $2, \mathrm{n}=1,172$} \\
\hline & $M$ & $S D$ & $M$ & $S D$ \\
\hline Age & 41.17 & 12.79 & 41.19 & 13.13 \\
\hline Gender & $n$ & $\%$ & $n$ & $\%$ \\
\hline Female & 811 & 70.9 & 813 & 69.4 \\
\hline Male & 327 & 28.6 & 355 & 30.3 \\
\hline Other & 6 & 0.52 & 4 & 0.34 \\
\hline \multicolumn{5}{|l|}{ Education level } \\
\hline 6 - 9 years of schooling & 4 & 0.35 & 3 & 0.26 \\
\hline $10-13$ years of schooling & 146 & 12.8 & 138 & 11.8 \\
\hline Completed vocational studies & 402 & 35.1 & 416 & 35.5 \\
\hline Completed studies & 551 & 48.2 & 572 & 48.8 \\
\hline Doctorate & 41 & 3.58 & 43 & 3.67 \\
\hline \multicolumn{5}{|c|}{ Average monthly household income ${ }^{a b}$} \\
\hline$<1,000$ Euro & 108 & 9.85 & 116 & 10.3 \\
\hline 1,000 to $<2,000$ Euro & 154 & 14.1 & 149 & 13.2 \\
\hline 2,000 to $<3,000$ Euro & 306 & 27.9 & 287 & 25.5 \\
\hline 3,000 to $<5,000$ Euro & 343 & 31.3 & 348 & 30.9 \\
\hline$\geq 5,000$ Euro & 185 & 16.9 & 225 & 20.0 \\
\hline \multicolumn{5}{|l|}{ Community } \\
\hline Large City & 666 & 58.2 & 687 & 58.6 \\
\hline Small city or town & 247 & 21.6 & 250 & 21.3 \\
\hline Suburb near a large city & 135 & 11.8 & 132 & 11.3 \\
\hline Rural area & 96 & 8.39 & 103 & 8.79 \\
\hline \multicolumn{5}{|c|}{ Risk for severe or life-threatening symptoms of corona virus } \\
\hline Yes & 251 & 21.9 & 253 & 21.6 \\
\hline No & 893 & 78.1 & 919 & 78.4 \\
\hline \multicolumn{5}{|l|}{ Mental disorder diagnosis } \\
\hline Yes (recovered) & 176 & 15.4 & 178 & 15.2 \\
\hline Yes (currently affected) & 92 & 8.04 & 94 & 8.02 \\
\hline No & 876 & 76.6 & 900 & 76.8 \\
\hline
\end{tabular}

Note. ${ }^{a}$ study $1: \mathrm{n}=1,096 .{ }^{\mathrm{b}}$ study $2: \mathrm{n}=1,125$. 
Table 2

Means, Standard Deviations and Factor Loadings for the Items of the Pandemic Coping Scale (Study 1, $\mathrm{n}=1,144$ German Adults)

\begin{tabular}{|c|c|c|c|c|c|c|c|c|}
\hline \multirow[t]{2}{*}{ Item } & \multirow[t]{2}{*}{$M$} & \multirow[t]{2}{*}{$S D$} & \multirow[t]{2}{*}{ Skewness } & \multirow[t]{2}{*}{ Kurtosis } & \multicolumn{4}{|c|}{ Factor loadings } \\
\hline & & & & & $\begin{array}{l}\text { Factor } 1 \\
\text {,Healthy } \\
\text { Lifestyle' }\end{array}$ & $\begin{array}{l}\text { Factor } 2 \\
\text { 'Joyful } \\
\text { Activities' }\end{array}$ & $\begin{array}{l}\text { Factor } 3 \\
\text {,Daily } \\
\text { Structure' }\end{array}$ & $\begin{array}{l}\text { Factor } 4 \\
\text { 'Prevention } \\
\text { Adherence' }\end{array}$ \\
\hline Item 3: Paying attention to a healthy diet & 2.07 & 0.90 & -0.65 & -0.42 & .60 & -.11 & -.08 & .17 \\
\hline Item 4: Exercising or taking a walk & 1.97 & 0.98 & -0.42 & -0.96 & .52 & .02 & -.06 & .01 \\
\hline Item 5: Paying attention to good sleeping habits & 1.67 & 1.02 & -2.68 & 7.33 & .80 & -.07 & -.09 & -.05 \\
\hline Item 6: Paying attention to take enough breaks & 1.44 & 1.06 & -1.56 & 1.73 & .69 & .17 & .11 & -.04 \\
\hline Item 7: I have been relaxing & 0.84 & 1.01 & -0.21 & -1.05 & .47 & .20 & .05 & -.02 \\
\hline Item 8: Doing something useful & 1.91 & 0.94 & -0.21 & -0.87 & .09 & .37 & -.07 & .09 \\
\hline Item 9: Doing something that I enjoy & 1.94 & 0.88 & 0.08 & -1.18 & .10 & .70 & .04 & -.09 \\
\hline $\begin{array}{l}\text { Item } 12 \text { : Spending a good time with loved } \\
\text { ones/friends/pet }\end{array}$ & 1.94 & 1.03 & 0.89 & -0.41 & .01 & .40 & -.13 & -.05 \\
\hline $\begin{array}{l}\text { Item 13: Spending a good time with loved } \\
\text { ones/friends through digital media }\end{array}$ & 1.79 & 0.94 & -0.34 & -0.83 & -.01 & .47 & -.02 & .16 \\
\hline Item 10: Structuring my day & 1.90 & 0.97 & -0.35 & -0.93 & .02 & .09 & -.85 & -.02 \\
\hline $\begin{array}{l}\text { Item 11: Paying attention to maintain my daily } \\
\text { routine }\end{array}$ & 1.95 & .999 & -0.45 & -0.83 & .03 & .03 & -.81 & .01 \\
\hline $\begin{array}{l}\text { Item 1: Following the recommendations to limit } \\
\text { spread of coronavirus }\end{array}$ & 2.82 & .490 & -0.51 & -0.85 & -.02 & .06 & .04 & .62 \\
\hline $\begin{array}{l}\text { Item 2: Informing myself about the current state of } \\
\text { the pandemic }\end{array}$ & 2.62 & .668 & -0.08 & -1.05 & .04 & -.02 & -.04 & .52 \\
\hline
\end{tabular}

Table 3

Global Fit Indices of the Confirmatory Factor Analysis for Model 1 and Model 2 (Study 2, $n=1,172$ participants)

\begin{tabular}{|c|c|c|c|c|c|c|c|c|c|c|}
\hline Global Fit Index & $x^{2}$ & df & $p$ & normed $\chi^{2}$ & RMSA & $p$ RMSA & RMSEA $90 \% \mathrm{Cl}$ & SRMR & TLI & $\mathrm{CFI}$ \\
\hline Model 1 & 366.97 & 59 & $<.001$ & 6.22 & .067 & $<.001$ & $.060-.073$ & .043 & .902 & .926 \\
\hline Model 2 & 373.33 & 61 & $<.001$ & 6.12 & .066 & $<.001$ & $.060-.073$ & .043 & .904 & .925 \\
\hline
\end{tabular}

Note. $\mathrm{df}$ = degrees of freedom; RMSEA = Root Mean Square Error of Approximation; $\mathrm{Cl}$ = Confidence Interval; SRMR = Standardized Root Mean Residual; TLI= Tucker-Lewis Index; CFI = Comparative Fit Index.

\section{Figures}




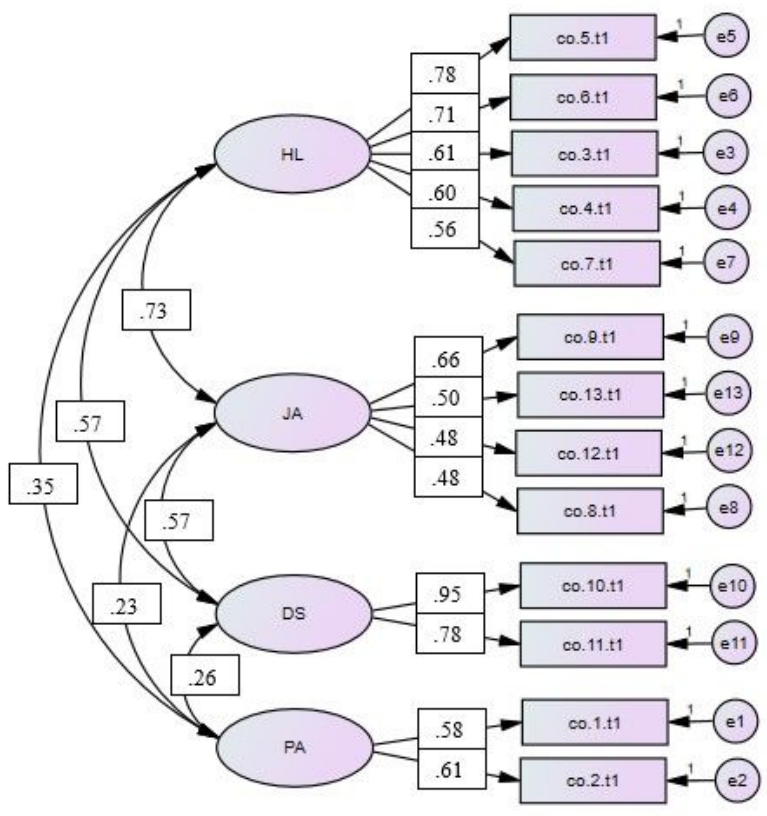

Figure 1

Factor Loadings of Model 1 Consisting of Four First-order Factors

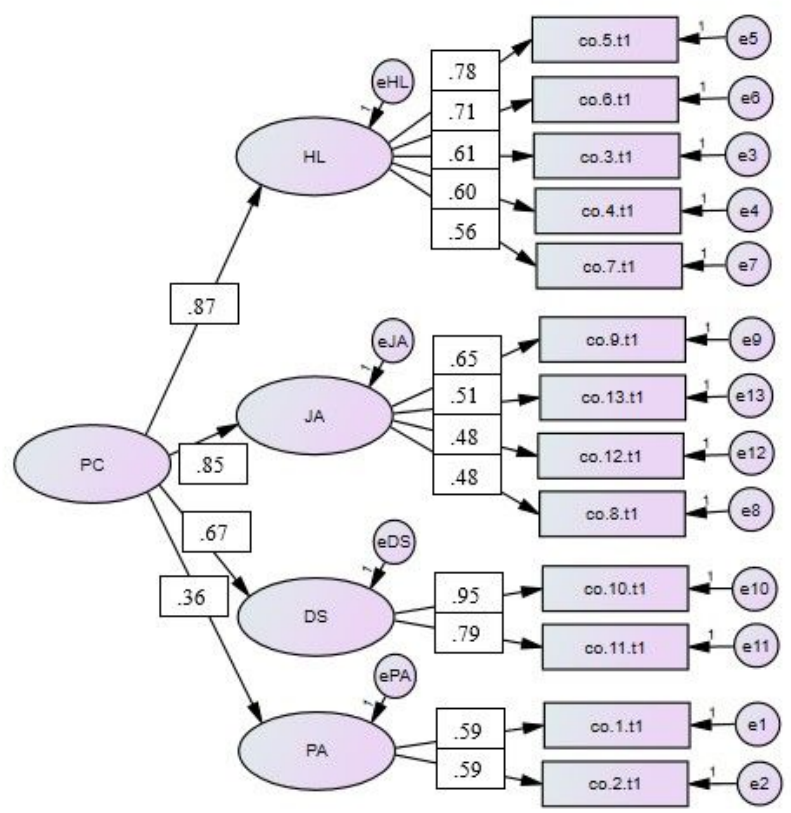

Figure 2

Factor Loadings of Model 2 Consisting of Four First-order Factors and a Second-order General Factor

\section{Supplementary Files}

This is a list of supplementary files associated with this preprint. Click to download.

- Supplements.docx 